\title{
Leader Power and Agency-Communion Orientations as Moderators of the Effects of Organizational Characteristics on Workplace Bullying
}

\author{
Jeffery D. Houghton ${ }^{1} \cdot$ Richard A. Oxarart ${ }^{1} \cdot$ Joyce Thompson Heames ${ }^{2}$. \\ M. Ronald Buckley ${ }^{3}$. Jerry A. Carbo ${ }^{4}$
}

Accepted: 1 June 2021 / Published online: 15 June 2021

(c) The Author(s), under exclusive licence to Springer Science+Business Media, LLC, part of Springer Nature 2021

\begin{abstract}
This conceptual paper suggests that the distinction between an autocratic and democratic leadership orientation may serve as an important moderator of the relationship between key organizational characteristics and workplace bullying. More specifically, we explore leader autocratic vs. democratic power orientations and leader agentic vs. communal orientations as the theoretical bases for developing a new model of perceived leadership orientation as a moderator of the relationships between certain key organizational characteristics and perceptions of workplace bullying behavior. Our model proposes differential moderating effects for both leader autocratic-democratic power orientation and leader agenticcommunal orientation. Particularly, we contend that democratic and communal leadership orientations may lead to fewer perceptions of bullying in the workplace. We conclude with a discussion of our model's practical implications and suggestions for future research on this subject.
\end{abstract}

Keywords Workplace Bullying · Autocratic Leadership Orientation · Democratic Leadership Orientation · Agentic Leadership Orientation · Communal Leadership Orientation

\section{Introduction}

In his book, The Asshole Survival Guide: How to Deal with People Who Treat You Like Dirt, Robert Sutton (2018) painstakingly illustrates the complexity, deviousness, and prevalence of organizational miscreants at work. They are at work and they

Richard A. Oxarart

rao0009@mix.wvu.edu

1 John Chambers College of Business \& Economics, West Virginia University, Morgantown, WV 26506, US

2 Campbell School of Business, Berry College, MT Berry, US

3 Price College of Business, University of Oklahoma, Norman, US

4 John L. Grove College of Business, Shippensburg University, Shippensburg, US 
are not helping. In fact, Sutton has developed a measure of TCA (the Total Cost of Assholes) and, not surprisingly, the TCA is a significant amount. Doubtlessly, as this illustrates, counterproductive behaviors are costly to an organization. Importantly, since the late nineties, workplace bullying, just one form of counterproductive behavior, has been gaining increased attention and causing growing concern. The Workplace Bullying Institute (2017) reports on a survey showing that over 60.3 million workers in the United States are influenced by bullying either as a witness or a victim. That is more than one third of the entire workforce. Workplace bullying is a serious and pervasive problem that can have devastating effects on the targets of the bullying, their organizations, and society at large. Despite the apparent prevalence and severity of bullying behaviors, researchers are still defining the nomological network surrounding this variable. There is a need to find out more about the antecedents and consequences of this counterproductive work behavior (Carbo, 2017; Wech et al., 2020).

Although definitions of bullying continue to be refined (e.g., Fox \& Cowan, 2015), Farrington (1993, p. 384) points out that "there is widespread agreement that bullying includes several key elements: physical, verbal or psychological attack or intimidation that is intended to cause fear, distress or harm to the victim; an imbalance of power...absence of provocation ...repeated incidents." One of the more commonly accepted definitions of workplace bullying is:

"situations where an employee repeatedly and over a prolonged time period is exposed to harassing behavior from one or more colleagues (including subordinates and leaders) and where the targeted person is unable to defend him-/herself against this systematic mistreatment." (Nielsen \& Einarsen, 2018, p. 73).

More specifically, bullying behaviors range from gossiping about, yelling at, or ignoring a person, to socially isolating an individual. The outcomes of workplace bullying are reportedly consistent and the effects of workplace bullying on the careers and personal lives of the victims can indeed be severe. Einarsen (1999, p. 16) suggests that bullying may be "a more crippling and devastating problem for employees than all other work-related stress put together..." Bullying research shows a clear connection between adverse health and workplace bullying, suggesting that bullying may result in stress-related illnesses that can have seriously negative career implications (Park \& Ono, 2017). For example, a survey of Quebec workers found that the average psychological distress score for the victims of bullying was 140 percent higher than for non-victims, with 45.5 percent of the victims experiencing depression severe enough to require medical treatment (Parkes, 2004). A number of these health related consequences may interfere with a target's ability to be productive at work including heightened levels of anxiety, depression, burnout, frustration, helplessness, insomnia, nervous symptoms, melancholy, apathy, socio-phobia, negative emotions such as anger, resentment, and fear, difficulty concentrating, and lowered self-esteem and self-efficacy (e.g., Keashley \& Neuman, 2004; Lo Presti et al., 2019; Rayner et al., 2002).

Davenport et al. (1999) view bullying as an escalating process that can be divided into three distinct degrees with differential effects on the victim as follows:

- First degree - crying, occasional sleep difficulties, irritability, lack of concentration

- Second Degree - high blood pressure, persistent sleep difficulties, gastro-intestinal problems, concentration difficulties, excessive weight gain or loss, depression, alcohol or drug abuse, avoidance of the workplace, uncharacteristic fearfulness.

- Third Degree - severe depression, panic attacks, heart attacks, other severe illness, accidents, suicide attempts, violence directed at third parties. 
The physical and mental health effects of bullying can be quite pronounced, even in the early stages of a bullying scenario. Bullying has even been linked to symptoms consistent with post-traumatic stress syndrome-type symptoms, as well as suicidal thoughts and attempts. Indeed, there is evidence that some victims of bullying do in fact end up committing suicide (Mikkelsen \& Einarsen, 2001; Miller et al., 2019; C. Rayner et al., 2002). As Davenport et al., (1999, p. 33) suggest, "for the victim, death -through illness or suicide -may be the final chapter in the mobbing [bullying] story."

Clearly, the effects of workplace bullying can be devastating to the targets of such behavior, but the effects on their organizations are similarly disastrous. Workplace bullying can lead to tragic events ranging from the report of two separate airline accidents that resulted from flight crews that were afraid to question pilot decisions, to life threatening medical mistakes in the health care industry where the stress and fear created by bullying interfered with medical practices and procedures (Keashley \& Neuman, 2004). Even when the effects are not catastrophic, they may still have a substantially negative impact on individual behaviors and organizational outcomes (e.g., Valentine et al., 2017). For instance, one survey of bullying targets indicated that more than half lost work time as a result of the bullying, more than one third reduced their commitment to the organization, more than one fourth lost work time trying to avoid the bully, nearly one fourth decreased their effort at work, and 12 percent changed jobs as a direct result of the bullying (Pearson et al., 2000). Another study found that $25 \%$ of bullying victims eventually quit their jobs (Sheehan et al., 1999). In addition, lost productivity, higher turnover, and employee lawsuits are among the negative organizational outcomes that may be associated with workplace bullying (e.g., Carbo, 2017; Martin \& LaVan, 2010). Victims of bullying often estimate that they are working at only about $85 \%$ of their normal capacity (Hoel et al., 2001) and by some estimates 5-6 billion dollars is lost annually in the U.S. alone due to "real or perceived abuse of employees by employers" (Keashley \& Neuman, 2004). Cascio and Boudreau (2008) outline the dollar costs associated with these negative job-related outcomes and they are quite staggering.

\section{Organizational Factors that Contribute to Workplace Bullying}

Einarsen (1999) suggests that bullying will only occur if bullies believe they have the sanction or at least, the implicit consent of coworkers and superiors to exhibit bad behavior. Some researchers have submitted that tolerating bullying shifts the socially accepted norms of the organization and that civil behavior can quickly morph into incivility and bullying behaviors (Andersson \& Pearson, 1999). O’Leary-Kelly et al. (1996) conceptualized a model of organization motivated aggression, which focused on actions and outcomes instigated by characteristic and situations in the organization that led to aggressive behaviors. The motivation behind workplace bullying appears to be power driven, based in jealousy and greed with the bully seeking positional, personal, or emotional power over the victim. Thus, it is important to consider the environmental cues or organizational characteristics that might perpetuate workplace bullying.

One potential reason for bullying in organizations is the long-standing managerial practice of employing bullying as a supervisory tool (McCarthy \& Mayhew, 2004). As reflected in Jerry Useem's (2015) The Atlantic article "Why it Pays to be a Jerk," management by terror is a time-honored tradition that is generally accepted by organizations so long as the offenders are adding to the bottom line. Organizations may recognize the benefits of these 
practices of management through intimidation, while at the same time, not fully calculating the costs. According to McCarthy and Mayhew, "most corporations do not presently account for the costs of bullying and occupational violence in a comprehensive manner" (2004, p. 56). Other organizational factors have also been linked to workplace bullying such as poor work design, deficiencies in leadership behavior, socially exposed victims and low moral standards (K. Einarsen et al., 2017; Heames et al., 2006; Leymann, 1996; Valentine et al., 2017). The lack of job security and a lack of trust in management may also lead to higher workplace bullying rates. In addition, Einarsen (1999) found that the lack of constructive leadership, the lack of autonomy and high levels of role conflict were all associated with higher bullying incidents.

According to Rayner and colleagues (2002), poor conflict resolution systems may lead to conflict, which can evolve into bullying. Davenport et al. (1999) listed several organizational factors that may contribute to workplace bullying and suggested that the increased economic pressures of non-profits might explain why bullying is more prevalent in a nonprofit setting. They further suggested that a focus on the bottom line at the expense of employees, a highly hierarchical structure, a lack of an open door policy, poor communication and conflict resolution systems, weak leadership, scapegoat mentalities, little or no teamwork, poor diversity training, a stress intensive workforce, monotony and disbelief by managers may all contribute to a culture of mobbing [bullying] (Davenport et al., 1999). Harvey et al. (2006) proposed that the dynamic environment of work, time pressures on managers, the growing diversity in the workplace, and the downsizing and flattening of organizations have contributed to the increase in workplace bullying.

McCarthy and Mayhew (2004, p. 81) argue that organizations may create their bullies "where fear and hopelessness are overwhelming and resentment denied remedies may be projected through traditional construction of evil in targeting violence at perpetrators." Several studies have shown that the counterproductive behavior of a bully can be one of the most challenging interpersonal conflicts in groups and is driven by contemporary business pressures and stress (see Einarsen, 1999; Einarsen et al., 2010; Koopman et al., 2020; Luzio-Lockett, 1995; Tepper, 2000; Tepper et al., 2001; Zapf, 1999). The typical workplace contains a substantial amount of built-in interpersonal disparity that makes it ripe for workplace bullying. The merging of employees with different cultures, beliefs, values and attitudes provides an environment in which conflict and bullying is likely to arise. LuzioLockett (1995, p. 12) referred to the workplace as group-oriented settings that are typified by "differences of opinions, a competition for power and territoriality, jealousy, prejudice, envy, and problematic group dynamics." Other researchers have analyzed the workplace through the lens of relational stress issues and suggest that they are influential in perpetrating deviant behavior such as bullying (Agervold \& Mikkelsen, 2004; Ståle Einarsen, 2000; Ståle Einarsen \& Skogstad, 1996; Heames et al., 2006; Nabe-Nielsen et al., 2017). Their arguments suggest that organizational structure, group norms, class discrepancies, and the resulting strained relationships may spiral into destructive behavior that can lead to bullying.

Although a number of organizational characteristics have been associated with bullying as outlined above, in the current paper we will focus our attention on four key organizational characteristics that have been identified as promoting bullying behaviors in the workplace (Heames et al., 2006). These key characteristics include deficiencies in leadership behavior, deficiencies in work design, a socially exposed victim, and a low morale standard. Deficiencies in leadership behavior include the lack of training other supervisors in how to identify and deal with bullying behavior and/or personally engaging in bullying behaviors. Deficiencies in work design involve inadequate management of physical work 
environments such as isolated or poorly lighted areas that may facilitate bullying behaviors. Victims become socially exposed when an organization and its leaders create a climate conducive to bullying by not taking appropriate actions to stop these kinds of inappropriate behaviors or when the victim is an undocumented worker with no legal status or ability to complain. Finally, low morale standard occurs when bullying is tolerated and expected, leading to a demoralized workforce (Harvey et al., 2006).

The harmful effects of workplace bullying on organizational productivity, profitability, and employee turnover have been well documented (Cullinan et al., 2020; Ståle Einarsen \& Skogstad, 1996; Leymann, 1996; Nabe-Nielsen et al., 2017; Charlotte Rayner, 1997; Charlotte Rayner \& Cooper, 1997). What needs additional analysis is the relationship between bullying and the culture of the organization. For example, the type of leadership encouraged in an organization may play a significant role in reducing or promoting bullying behavior. The responsibility for recognizing and managing the deviant behaviors that develop within the organization lies with organizational leadership as it shapes the culture of the organization. Some suggest that by not taking action, organizations 'legitimize' and 'institutionalize' bullying through their leadership's silence (B. Ashforth, 1994; B. E. Ashforth, 2009; Liefooghe \& Mac Davey, 2001; Zhang \& Leidner, 2018). Workplace bullying is generally perceived as involving unendurable and unethical behaviors that can damage a corporation's associations and reputation if left unconstrained (Paine, 1994). Goldberg (1998) suggests that for companies to achieve long-term success, they must possess both "business competency" and an "internal and external social conscience." Indeed, scholars often affirm that organizations have a clear responsibility to reduce bullying behavior among its members (Dietz et al., 2003; Hutchinson, 2009; Paine, 1994). This discussion suggests a need for a better understanding of leadership's role in either promoting or attenuating workplace bullying.

In the following section, we explore what leadership orientations might facilitate bullying events or moderate the relationship between organization characteristics and workplace bullying behavior. We employ the theoretical conceptualizations of leader autocratic-democratic power orientation and leader agentic-communal orientation with supporting empirical research findings to develop a model of the moderating effects of leader orientations on the relationship between key organizational characteristics and perceptions of workplace bullying (shown in Fig. 1) along with accompanying research propositions.

\section{The Moderating Effects of Leadership Orientation}

Leadership is a multifaceted construct with many nuances and subtleties. It is perhaps most often described as a basic process of influence toward the accomplishment of objectives (e.g., Bass, 1960; Katz \& Kahn, 1966; Yukl, 1998). Through the years, to explore and better understand this process, theorists have identified key categories of leader behaviors that help to distinguish distinctive leadership orientations. For example, building upon the works of earlier scholars (e.g., Karmel, 1978; Lewin \& Lippitt, 1938), Bass and Bass (2008) suggested that leader behaviors can range from highly active and involved to completely passive and laissez-faire. Likewise, based on a number factor analytic studies (e.g., Edwards \& Rode, 1986; Sweeny et al., 1975), Bass and Bass (2008) determined that leadership behaviors also vary on a scale ranging from predominantly democratic to mostly autocratic. Working along similar lines, Stewart and Manz (1995) developed and presented a typology of leader power orientation and leader involvement. We utilize this model as a 


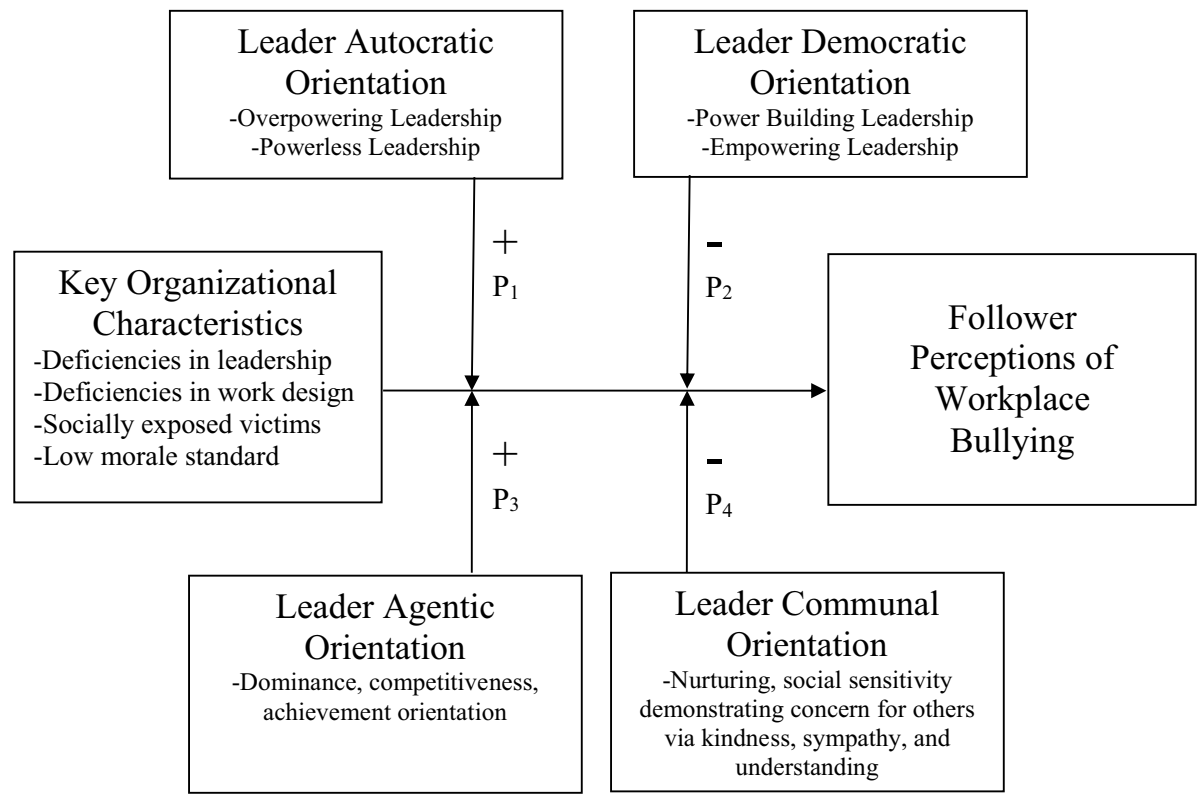

Fig. 1 A Model of Leader Power and Agency-Communion Orientations as a Moderators of the Effects of Organizational Characteristics on Perceptions of Workplace Bullying

framework for understanding the moderating effects of perceived leadership orientation on the relationship between key organizational characteristics and workplace bullying.

Within the Stewart and Manz (1995) typology, the dimensions of leader involvement (ranging from passive to active) and leader power orientation (ranging from democratic to autocratic) combine to produce four distinct leadership types. Overpowering leadership occurs when a leader engages in active and autocratic leadership behaviors. This type of leadership is labeled "overpowering" because it often has an overwhelming effect, resulting in submissive, dependent and compliant followers (Stewart \& Manz, 1995; Stewart et al., 2011). The overpowering leader is characterized by certain behaviors including instruction and command, coercion, intimidation and non-contingent reprimand (Pearce et al., 2003). Followers tend to respond with a fear-based compliance (Manz \& Sims, 2001). Empirical research findings have provided evidence supporting a relationship between overpowering, autocratic leadership and workplace bullying (e.g., Hoel et al., 2010).

In addition, the overpowering leader is also similar to what some have called the destructive leader (e.g., Einarsen et al., 2007; Ferris et al., 2007; Fosse et al., 2019; Mackey et al., 2019). Destructive leadership involves systematic behavior that undermines and/or sabotages the organization's or subordinate's goals or well-being (Ståle Einarsen et al., 2007). Destructive leadership may further be divided into three distinct types (Ståle Einarsen et al., 2007). Tyrannical leadership involves behavior that supports the organization but undermines the subordinate. Supportive-disloyal leadership is supportive of the subordinate but disloyal to the organization. Derailed leadership supports neither the organization nor the subordinate. Several researchers have suggested a relationship between destructive leadership and workplace bullying (e.g., Einarsen et al., 2007; Harvey et al., 2007). For example, Hauge et al. (2007) reported a strong relationship between tyrannical destructive leadership and bullying. Ferris and colleagues (2007) even suggest that destructive leaders may engage 
in bullying for strategic purposes in specific situations in order to produce desired results. Given the intimidating, coercive and manipulative nature of the overpowering leader, it seems reasonable to suggest that this type of leadership may intensify the effects of key organizational characteristics that may lead to bullying.

In contrast to the active and aggressive approach taken by the autocratic overpowering leader, powerless leadership occurs when an autocratic leader takes a passive, handsoff approach to leading. Also referred to as the laissez-faire type of leader (e.g., Lewin et al., 1939; Skogstad et al., 2007; Wellman et al., 2019), this type of leader may distance themselves psychologically from followers while still controlling followers through intermittent sanctions and punishment (Stewart \& Manz, 1995). The powerless or laissez-faire leadership type may result in decreased follower productivity (Pelz, 1956), satisfaction (Aspergren, 1963), and affective commitment (Robert \& Vandenberghe, 2020). Moreover, empirical research findings provide some evidence in support of both direct and moderating relationship between laissez-faire leadership and workplace bullying (Ågotnes et al., 2018; Glambek et al., 2018; Hauge et al., 2007; Hoel et al., 2010; Skogstad et al., 2007). Therefore, it seems likely that a powerless, hands-off leadership approach could magnify the effects of key organizational characteristics that may lead to bullying. Based on these theoretical and empirical bases, we propose that both the active, overpowering and the passive, laissez-faire powerless types of autocratic leadership will exacerbate the negative effects of key organizational characteristics on workplace bullying. Specifically:

Proposition 1: Follower perceptions of an autocratic leadership orientation (overpowering or powerless) moderates the relationship between key organizational characteristics and workplace bullying such that the relationship is stronger when perceptions of an autocratic leadership orientation are higher.

We now shift our focus away from autocratic leadership to consider the potential moderating effects of a democratic leader power orientation. Power building leadership involves an active and democratic approach that provides guidance and encouragement with a focus on follower learning and skill development (Stewart \& Manz, 1995). This leadership approach includes the behaviors of actively consulting, supporting, developing and mentoring followers (cf. Yukl, 1998). Often referred to as participative leadership (e.g., House, 1996), leaders with this active, democratic leadership orientation allow followers to influence decision-making processes by consulting with followers and considering their opinions before making final decisions and taking actions ( $\mathrm{Li}$ et al., 2018). Although followers are usually not yet at the stage of complete behavioral self-control, the power-building, participative leadership approach does tend to create an open and trusting culture that encourages some degree of follower self-reliance (Stewart \& Manz, 1995). Power building, participative leadership would therefore seem to attenuate the effects of key organizational characteristics on bullying. Although scant empirical evidence exists, one study reported a significant negative correlation between participative leadership and bullying, observed and self-reported (Hoel et al., 2010).

Empowering leadership represents a more passive approach to democratic leadership that more deeply empowers followers to take responsibility for personal behaviors, tasks and decision making processes (Amundsen \& Martinsen, 2014; Cheong et al., 2019; Pearce et al., 2003; Stewart \& Manz, 1995). With theoretical roots in social cognitive theory (Bandura, 1986) and participative goal setting research (Erez \& Arad, 1986), the empowered leadership approach encourages follower self-efficacy, participative goal setting, and self-leadership (Manz \& Sims, 2001; Pearce et al., 2003). The modeling of self-leadership behaviors to encourage followers to become more effective at leading 
themselves is an excellent example of a passive yet potentially powerful democratic leadership behavior (Manz \& Sims, 2001; Pearce \& Sims, 2002). Indeed, passive influence may have a more profound impact than more active forms of leadership because it encourages followers to engage in on-going learning and self-development (Stewart \& Manz, 1995). Although passive, laissez-faire leadership has been widely criticized (e.g., Skogstad et al., 2007), these criticisms do not hold particularly well in the context of an effectively executed passive form of democratic leadership (Stewart \& Manz, 1995). The empowered leadership approach is, therefore, more likely than other forms of laissez-faire leadership to create positive and functional environments in which followers take responsibility for personal behaviors and become accountable to one another. Given this type of environment, it appears less likely that key organizational characteristics will lead to bullying behaviors. Here again, very few empirical studies have explored the relationship between empowering leadership and bullying, although preliminary studies have reported negative correlations between empowering leadership dimensions and bullying (Magerøy et al., 2009; Skogstad et al., 2011). Given these theoretical and empirical foundations, we advance that both the active, participative power building and the passive, empowering types of democratic leadership will attenuate the negative effects of key organizational characteristics on workplace bullying. Accordingly:

Proposition 2: Follower perceptions of a democratic leadership orientation (power building or empowering) moderate the relationship between key organizational characteristics and workplace bullying such that the relationship is weaker when perceptions of a democratic leadership orientation are higher.

In addition to the autocratic-democratic leadership orientation, another leadership dimension that may influence workplace bullying is the agentic vs. communal leadership orientation (e.g., Abele, 2003; Kark et al., 2012). An agentic leadership orientation involves being dominant, assertive, competitive, active, decisive, and achievement orientated (Abele, 2003; Kark et al., 2012). Research suggests that dominance is associated with bullying perpetration (Farrell \& Dane, 2020). Meanwhile, other studies have shown that highly competitive organizational environments may lead to increased incidences of workplace bullying (Cheng \& Huang, 2019). Jacobson and her colleagues (K. J. Jacobson et al., 2014) also proposed that high levels of assertiveness within a national culture would be associated with high levels of organizational bullying within those cultures. Consequently, it seems reasonable to suggest that an agentic leadership orientation characterized by dominance, competitiveness, and assertiveness could intensify the negative effects of key organizational characteristics on workplace bullying. Hence:

Proposition 3: Follower perceptions of an agentic leadership orientation moderates the relationship between key organizational characteristics and workplace bullying such that the relationship is stronger when perceptions of an agentic leadership orientation are higher.

On the other hand, a communal leadership orientation entails being nurturing, caring, compassionate, and socially sensitive, while using kindness, sympathy, and understanding to show concern for others (Abele, 2003; Kark et al., 2012). The workplace bullying literature provides some evidence in support of a communal leadership orientation as a potential tool for reducing bullying in organizations. For instance, Olender (2017) used Watson's (2008) theory of human caring, which posits caring as a reciprocal phenomenon, hypothesizing and showing support for a significant inverse relationship between nurse manager caring and perceived workplace bullying in a healthcare setting. Similarly, Simpson et al. 
(2019) found support for their hypothesized negative relationships between organizational compassion and psychological safety and workplace bullying. Additionally, researchers tested and demonstrated support for a model in which a cluster of "moral" emotional traits, including empathic concern predicted workplace bullying perpetration (R. P. Jacobson et al., 2017). On the strength of this evidence, we forward that communal leadership orientation encompassing caring, compassion, and concern is likely to ameliorate the negative effects of key organizational characteristics on workplace bullying. Therefore:

Proposition 4: Follower perceptions of a communal leadership orientation moderates the relationship between key organizational characteristics and workplace bullying such that the relationship is weaker when perceptions of a communal leadership orientation are higher.

\section{Managerial Implications and Future Research}

Much of the past research examining the relationships between leadership behavior and workplace bullying has focused on the degree of leader involvement. These studies suggest that both highly active, destructive leadership behavior and completely passive, laissez-faire leadership behavior can promote workplace bullying behaviors (e.g., Hauge et al., 2007; Skogstad et al., 2007). However, this research provides very little insight into when and under what circumstance active and passive leadership styles will promote bullying behaviors. In an effort to explore this issue in greater depth, we utilized theoretical conceptualizations of leader autocratic-democratic power orientation and leader agenticcommunal orientation and supporting empirical research findings as moderators of the relationship between certain key organizational characteristics and perceptions of workplace bullying behavior.

Our model suggests that leader power orientation is one of the key factors determining whether an active or passive leadership style will lead to greater perceptions of workplace bullying. More specifically, we propose that an autocratic leadership orientation, whether active or passive, will cause key organizational factors to have a greater impact on perceptions of workplace bullying (Proposition 1). Likewise, we contend that democratic leadership orientations, whether active or passive, will attenuate the effects of key organizational factors on perceptions of workplace bullying (Proposition 2). Thus, our model suggests that, in general, democratic leadership behaviors including encouraging self-problem solving, individual initiative, self-observation, self-evaluation, self-reward, self-goal setting, opportunistic thinking, and efficacy expectations may lead to fewer perceptions of bullying in the workplace.

Although our model suggests that autocratic leadership orientations may lead to greater perception of workplace bullying, we do not mean to imply that autocratic leadership is entirely ineffective or inappropriate. Quite to the contrary, an autocratic, directive leadership approach may be preferred in times of crisis or in extremely urgent situations, as well as for unstructured task situations (Houghton \& Yoho, 2005). Similarly, directive, task-oriented leadership may be preferred in situations where followers are at low levels of readiness or development (Hersey et al., 2007; Houghton \& Yoho, 2005). For example, during times of crisis, such as the current worldwide COVID-19 pandemic, specific and directive task-oriented instructions are often necessary and preferred. As mentioned earlier, even so-called destructive leadership may be strategically employed to create positive outcomes and benefits (Ferris et al., 2007). However, organizational leaders should 
understand that the situational benefits of employing an autocratic leadership approach may be offset to a certain extent by the costs associated with increased bullying behaviors. Bullying is clearly deleterious to performance and leaders should not attempt strategically to manipulate perceptions to the contrary. Rather, these leaders should carefully consider the costs and the ethical implications of consistently using the means of an autocratic leadership style to justify effective ends.

Our model further suggests that a leader's agentic vs. communal orientation may further moderate the relationship between organizational risk factors for bullying and individual bullying perceptions. More precisely, we propose that an agentic leadership orientation, as reflected in dominant, assertive, and competitive behaviors, will enhance the negative effects of key organizational factors on perceptions of workplace bullying (Proposition 3). Along similar lines, we posit that communal leadership orientations, including caring, compassionate, and empathetic behaviors, will minimize the effects of key organizational factors on perceptions of workplace bullying (Proposition 4).

Recent research suggests that there are gender differences in terms of exposure to bullying behaviors in the workplace (Maidaniuc-Chirilă, 2019). According to social role theory, people often hold prescriptive expectations for others' gender role behaviors based on traditional divisions of labor that generally associated men with breadwinner roles and women with homemaker roles (Eagly \& Wood, 2012). Based on these traditional roles, men are thought and expected to be more agentic, assertive and competitive than women, while women are perceived and expected to be more communal, caring, and nurturing than men (Paustian-Underdahl et al., 2014). Research on gender and workplace bullying has generally found the subordinates working under a male leader perceive more workplace bullying than those working under female leaders (e.g., Wang \& Hsieh, 2016). Consequently, such research, coupled with our model, suggests that male leaders should work especially hard to engage in communal leadership behaviors, which may not be their natural tendency based on traditional gender roles and expectations, to help limit perceptions of workplace bullying. Women in leadership roles, on the other hand, feeling pressure to adopt more agentic behaviors to overcome negative gender-based biases and stereotypes, should be careful not to exacerbate workplace bullying perceptions unintentionally, but rather should strive to balance communal and agentic orientations, which research suggests could confer them an advantage (Rosette \& Tost, 2010).

Our model also implies the possibility of specific leadership development interventions aimed at reducing workplace bullying. Recently, Caponecchia et al. (2020) developed and presented a taxonomy of workplace bullying intervention types. They mentioned leadership as one possible factor relating to bullying that could be targeted by organizational interventions (Caponecchia et al., 2020, p. 106) but did not provide specific details. In contrast, our model suggests that leadership development interventions designed to reduce workplace bullying could focus on encouraging more empowering and communal leadership behaviors, while explaining the tradeoff between the benefits and costs of using more autocratic and agentic approaches.

Future research should strive to empirically investigate the relationships suggested in our model in an organization setting. To facilitate such research, the autocratic-democratic leadership orientation dimension could be measured using items employed by Pearce et al. (2003). The agentic-communal leadership orientation dimension could be measured with items developed by Trapnell and Paulhus (2012). Perception of workplace bullying behaviors could be measured using the Negative Acts Questionnaire (NAQ; Einarsen et al., 2009). Furthermore, future research should endeavor to collect data on dyadic pairs to better understand how bullying behaviors are perceived by the various parties involved (Taylor 
et al., 2018). Finally, organizational characteristics including deficiencies in leadership, deficiencies in work design, a socially exposed victim and a low morale standard would also need to be measured. The moderating effects of leadership style on the relationship between organizational characteristics and perceptions of workplace bullying could be examined using statistical software such as the PROCESS macro (Hayes, 2017). Through future research endeavors such as this, we may gain a better understanding of the influential role of leadership in the context of workplace bullying.

\section{Declarations}

Conflicts of Interest All authors declare that they have no conflicts of interest.

\section{References}

Abele, A. E. (2003). The Dynamics of Masculine-Agentic and Feminine-Communal Traits: Findings from a Prospective Study. Journal of Personality and Social Psychology. https://doi.org/10.1037/0022-3514. 85.4.768

Agervold, M., \& Mikkelsen, E. G. (2004). Relationships between bullying, psychosocial work environment and individual stress reactions. Work and Stress. https://doi.org/10.1080/02678370412331319794

Ågotnes, K. W., Einarsen, S. V., Hetland, J., \& Skogstad, A. (2018). The moderating effect of laissez-faire leadership on the relationship between co-worker conflicts and new cases of workplace bullying: A true prospective design. Human Resource Management Journal. https://doi.org/10.1111/1748-8583. 12200

Amundsen, S., \& Martinsen, O. L. (2014). Self-other agreement in empowering leadership: Relationships with leader effectiveness and subordinates' job satisfaction and turnover intention. Leadership Quarterly. https://doi.org/10.1016/j.leaqua.2014.04.007

Andersson, L. M., \& Pearson, C. M. (1999). Tit for Tat? The Spiraling Effect of Incivility in the Workplace. Academy of Management Review, 24(3), 452-471. https://doi.org/10.5465/amr.1999.2202131

Ashforth, B. (1994). Petty Tyranny in Organizations. Human Relations. https://doi.org/10.1177/ 001872679404700701

Ashforth, B. E. (2009). Petty Tyranny in Organizations: A Preliminary Examination of Antecedents and Consequences. Canadian Journal of Administrative Sciences / Revue Canadienne Des Sciences De L'administration. https://doi.org/10.1111/j.1936-4490.1997.tb00124.x

Aspergren, R. E. (1963). A study of leadership behavior and its effects on morale and attitudes in selected elementary schools. Dissertation Abstracts, 23, 3708.

Bandura, A. (1986). Social foundations of thought and action : A social cognitive theory / Albert Bandura (p. 1986). Prentice-Hall.

Bass, B. M. (1960). Leadership, Psychology and Organizational Behavior. Harper.

Bass, B. M., \& Bass, R. (2008). Bass \& Stodgill's Handbook of Leadership: Theory, Research and Managerial Applications (4th ed.). Free Press.

Caponecchia, C., Branch, S., \& Murray, J. P. (2020). Development of a Taxonomy of Workplace Bullying Intervention Types: Informing Research Directions and Supporting Organizational Decision Making. Group \& Organization Management, 45(1), 103-133. https://doi.org/10.1177/1059601118820966

Carbo, J. A. (2017). Understanding, Defining and Eliminating Workplace Bullying: Assuring Dignity at Work. Routledge.

Cascio, W. F., \& Boudreau, J. (2008). Investing in People: Financial Impact of Human Resources Initiatives. Ft Press.

Cheng, H., \& Huang, K. (2019). Salute to the Black Sheep: The Legitimacy of Workplace Bulling from the Perspective of Organizational Cohesive Affinity and Organizational Competitiveness. International Journal of Organizational Innovation, 12(2), 230-238.

Cheong, M., Yammarino, F. J., Dionne, S. D., Spain, S. M., \& Tsai, C.-Y. (2019). A review of the effectiveness of empowering leadership. The Leadership Quarterly, 30(1), 34-58. https://doi.org/10.1016/j. leaqua.2018.08.005

Cullinan, J., Hodgins, M., Hogan, V., \& Pursell, L. (2020). The value of lost productivity from workplace bullying in Ireland. Occupational medicine (Oxford, England). https://doi.org/10.1093/occmed/kqaa067 
Davenport, N., Schwartz, R. D., \& Ellliot, G. P. (1999). Mobbing: Emotional Abuse in the American Workplace. Civil Society Publishing.

Dietz, J., Robinson, S. L., Folger, R., Baron, R. A., \& Schulz, M. (2003). The impact of community violence and an organization's procedural justice climate on workplace aggression. Academy of Management Journal. https://doi.org/10.2307/30040625

Eagly, A. H., \& Wood, W. (2012). Social role theory. Handbook of Theories of Social Psychology. https:// doi.org/10.4135/9781446249222.n49

Edwards, J. E., \& Rode, L. G. (1986). A Path Analytic Approach to the Construct Validation of Selected Leadership Scales. In Academy of Management.

Einarsen, K., Mykletun, R. J., Einarsen, S. V., Skogstad, A., \& Salin, D. (2017). Ethical infrastructure and successful handling of workplace bullying. Nordic Journal of Working Life Studies. https://doi.org/10. 18291/njwls.v7i1.81398

Einarsen, S. V., Hoel, H., Zapf, D., Cooper, C. L., Hoel, H., Zapf, D., \& Cooper, C. L. (2010). Bullying and Harassment in the Workplace : Theory, Research and Practice. Development of theory, research, and practice second edition. https://doi.org/10.1201/9780429462528

Einarsen, S., Hoel, H., \& Notelaers, G. (2009). Measuring exposure to bullying and harassment at work: Validity, factor structure and psychometric properties of the negative acts questionnaire-revised. Work and Stress. https://doi.org/10.1080/02678370902815673

Einarsen, S. (1999). The nature and causes of bullying at work. International Journal of Manpower. https:// doi.org/10.1108/01437729910268588

Einarsen, S. (2000). Harassment and bullying at work: A review of the Scandinavian approach. Aggression and Violent Behavior. https://doi.org/10.1016/S1359-1789(98)00043-3

Einarsen, S., Aasland, M. S., \& Skogstad, A. (2007). Destructive leadership behaviour: A definition and conceptual model. Leadership Quarterly. https://doi.org/10.1016/j.leaqua.2007.03.002

Einarsen, S., \& Skogstad, A. (1996). Bullying at work: Epidemiological findings in public and private organizations. European Journal of Work and Organizational Psychology. https://doi.org/10.1080/ 13594329608414854

Erez, M., \& Arad, R. (1986). Participative Goal-Setting. Social, Motivational, and Cognitive Factors. Journal of Applied Psychology. https://doi.org/10.1037/0021-9010.71.4.591

Farrell, A. H., \& Dane, A. V. (2020). Bullying, Victimization, and prosocial resource control strategies: Differential relations with dominance and alliance formation. Evolutionary Behavioral Sciences, 14(3), 270-283.

Farrington, D. P. (1993). Understanding and Preventing Bullying. Crime and Justice. https://doi.org/10. $1086 / 449217$

Ferris, G. R., Zinko, R., Brouer, R. L., Buckley, M. R., \& Harvey, M. G. (2007). Strategic bullying as a supplementary, balanced perspective on destructive leadership. Leadership Quarterly. https://doi.org/10. 1016/j.leaqua.2007.03.004

Fosse, T. H., Skogstad, A., Einarsen, S. V., \& Martinussen, M. (2019). Active and passive forms of destructive leadership in a military context: A systematic review and meta-analysis. European Journal of Work and Organizational Psychology, 28(5), 708-722. https://doi.org/10.1080/1359432X.2019. 1634550

Fox, S., \& Cowan, R. L. (2015). Revision of the workplace bullying checklist: The importance of human resource management's role in defining and addressing workplace bullying. Human Resource Management Journal. https://doi.org/10.1111/1748-8583.12049

Glambek, M., Skogstad, A., \& Einarsen, S. (2018). Workplace bullying, the development of job insecurity and the role of laissez-faire leadership: A two-wave moderated mediation study. Work and Stress. https://doi.org/10.1080/02678373.2018.1427815

Goldberg, R. (1998). Corporate image, business competency vs. social conscience. Cambridge, MA: Harvard University Press.

Harvey, M. G., Buckley, M. R., Heames, J. T., Zinko, R., Brouer, R. L., \& Ferris, G. R. (2007). A Bully as an Archetypal Destructive Leader. Journal of Leadership \& Organizational Studies. https://doi.org/ 10.1177/1071791907308217

Harvey, M. G., Heames, J. T., Richey, R. G., \& Leonard, N. (2006). Bullying: From the Playground to the Boardroom. Journal of Leadership \& Organizational Studies, 12(4), 1-11. https://doi.org/10.1177/ 107179190601200401

Hauge, L. J., Skogstad, A., \& Einarsen, S. (2007). Relationships between stressful work environments and bullying: Results of a large representative study. Work and Stress. https://doi.org/10.1080/ 02678370701705810

Hayes, A. F. (2017). Introduction to mediation, moderation, and conditional process analysis: A regressionbased approach. The Guilford Press. 
Heames, J. T., Harvey, M. G., \& Treadway, D. (2006). Status inconsistency: An antecedent to bullying behaviour in groups. International Journal of Human Resource Management. https://doi.org/10.1080/ 09585190500404952

Hersey, P., Blanchard, K. H., \& Johnson, D. E. (2007). Management of Organizational Behavior: Leading Human Resources (9th ed.). Prentice-Hall.

Hoel, H., Glasø, L., Hetland, J., Cooper, C. L., \& Einarsen, S. (2010). Leadership styles as predictors of self-reported and observed workplace bullying. British Journal of Management. https://doi.org/10. 1111/j.1467-8551.2009.00664.x

Hoel, H., Sparks, K., \& Cooper, C. L. (2001). The cost of violence/stress at work and the benefits of a violence/stress-free working environment. International Labour Organization.

Houghton, J. D., \& Yoho, S. K. (2005). Toward a Contingency Model of Leadership and Psychological Empowerment: When Should Self-Leadership Be Encouraged? Journal of Leadership \& Organizational Studies. https://doi.org/10.1177/107179190501100406

House, R. J. (1996). Path-goal theory of leadership: Lessons, legacy, and a reformulated theory. Leadership Quarterly. https://doi.org/10.1016/S1048-9843(96)90024-7

Hutchinson, M. (2009). Restorative approaches to workplace bullying: Educating nurses towards shared responsibility. Contemporary Nurse. https://doi.org/10.5172/conu.32.1-2.147

Institute, W. B. (2017). Workplace Bullying Institute. https://workplacebullying.org/download/2017-wbi/

Jacobson, K. J., Hood, J. N., \& Van Buren, H. J. (2014). Workplace bullying across cultures: A research agenda. International Journal of Cross Cultural Management. https://doi.org/10.1177/1470595813494192

Jacobson, R. P., Hood, J. N., \& Jacobson, K. J. L. (2017). The Effects of Moral Emotional Traits on Workplace Bullying Perpetration. Ethics and Behavior. https://doi.org/10.1080/10508422.2016.1182026

Kark, R., Waismel-Manor, R., \& Shamir, B. (2012). Does valuing androgyny and femininity lead to a female advantage? The relationship between gender-role, transformational leadership and identification. Leadership Quarterly. https://doi.org/10.1016/j.leaqua.2011.12.012

Karmel, B. (1978). Leadership: A Challenge to Traditional Research Methods and Assumptions. Academy of Management Review, 3(3), 475-482. https://doi.org/10.5465/amr.1978.4305735

Katz, D., \& Kahn, R. L. (1966). The Social Psychology of Organizations. Wiley.

Keashley, L., \& Neuman, J. H. (2004). Bullying in the workplace: Its impact and management. Employee Rights and Employment Policy Journal, 8, 335-346.

Koopman, J., Rosen, C. C., Gabriel, A. S., Puranik, H., Johnson, R. E., \& Ferris, D. L. (2020). Why and for whom does the pressure to help hurt others? Affective and cognitive mechanisms linking helping pressure to workplace deviance. https://doi.org/10.1111/peps.12354

Lewin, K., \& Lippitt, R. (1938). An Experimental Approach to the Study of Autocracy and Democracy: A Preliminary Note. Sociometry, 1(3/4), 292. https://doi.org/10.2307/2785585

Lewin, K., Lippitt, R., \& White, R. K. (1939). Patterns of Aggressive Behavior in Experimentally Created "Social Climates." The Journal of Social Psychology, 10(2), 269-299. https://doi.org/10.1080/00224545. 1939.9713366

Leymann, H. (1996). The content and development of mobbing at work. European Journal of Work and Organizational Psychology, 5(2), 165-184. https://doi.org/10.1080/13594329608414853

Li, G., Liu, H., \& Luo, Y. (2018). Directive versus participative leadership: Dispositional antecedents and team consequences. Journal of Occupational and Organizational Psychology. https://doi.org/10. 1111/joop.12213

Liefooghe, A. P. D., \& Mac Davey, K. (2001). Accounts of workplace bullying: The role of the organization. European Journal of Work and Organizational Psychology, 10(4), 375-392. https://doi.org/10.1080/ 13594320143000762

Lo Presti, A., Pappone, P., \& Landolfi, A. (2019). The associations between workplace bullying and physical or psychological negative symptoms: Anxiety and depression as mediators. Europe's Journal of Psychology. https://doi.org/10.5964/ejop.v15i4.1733

Luzio-Lockett, A. (1995). Enhancing relationships within organizations an examination of a proactive approach to "bullying at work." Employee Counselling Today. https://doi.org/10.1108/13665629510081520

Mackey, J. D., McAllister, C. P., Maher, L. P., \& Wang, G. (2019). Leaders and followers behaving badly: A meta-analytic examination of curvilinear relationships between destructive leadership and followers' workplace behaviors. Personnel Psychology. https://doi.org/10.1111/peps.12286

Magerøy, N., Lau, B., Riise, T., \& Moen, B. E. (2009). Association of psychosocial factors and bullying at individual and department levels among naval military personnel. Journal of Psychosomatic Research. https://doi.org/10.1016/j.jpsychores.2008.10.009

Maidaniuc-Chirilă, T. (2019). Gender differences in workplace bullying exposure. Journal of Psychological and Educational Research. 
Manz, C. C., \& Sims, H. P. J. (2001). The New SuperLeadership: Leading Others to Lead Themselves. Berrett-Koehler.

Martin, W., \& LaVan, H. (2010). Workplace Bullying: A Review of Litigated Cases. Employee Responsibilities and Rights Journal, 22(3), 175-194. https://doi.org/10.1007/s10672-009-9140-4

McCarthy, P., \& Mayhew, C. (2004). Safeguarding the Organization Against Violence and Bullying. Palgrave Macmillan.

Mikkelsen, E. G., \& Einarsen, S. (2001). Bullying in Danish work-life: Prevalence and health correlates. European Journal of Work and Organizational Psychology, 10(4), 393-413. https://doi.org/10. 1080/13594320143000816

Miller, P., Brook, L., Stomski, N. J., Ditchburn, G., \& Morrison, P. (2019). Depression, suicide risk, and workplace bullying: A comparative study of fly-in, fly-out and residential resource workers in Australia. Australian Health Review. https://doi.org/10.1071/AH18155

Nabe-Nielsen, K., Grynderup, M. B., Conway, P. M., Clausen, T., Bonde, J. P., Garde, A. H., et al. (2017). The Role of Psychological Stress Reactions in the Longitudinal Relation Between Workplace Bullying and Turnover. Journal of Occupational and Environmental Medicine, 59(7), 665672. https://doi.org/10.1097/JOM.0000000000001050

Nielsen, M. B., \& Einarsen, S. V. (2018). What we know, what we do not know, and what we should and could have known about workplace bullying: An overview of the literature and agenda for future research. Aggression and Violent Behavior, 42, 71-83. https://doi.org/10.1016/j.avb.2018.06.007

O'Leary-Kelly, A. M., Griffin, R. W., \& Glew, D. J. (1996). Organization-motivated aggression: A research framework. Academy of Management Review. https://doi.org/10.5465/AMR.1996.9602161571

Olender, L. (2017). The relationship between and factors influencing staff nurses' perceptions of nurse manager caring and exposure to workplace bullying in multiple healthcare settings. JONA: the Journal of Nursing Administration, 47(10), 501-507. https://doi.org/10.1097/NNA.0000000000000522

Paine, L. (1994). Managing for organizational integrity. Harvard Business Review. https://doi.org/10. $1177 / 105256299301700404$

Park, J. H., \& Ono, M. (2017). Effects of workplace bullying on work engagement and health: The mediating role of job insecurity. International Journal of Human Resource Management. https://doi. org/10.1080/09585192.2016.1155164

Parkes, D. (2004). Targeting workplace harassment in Quebec: On exporting a legislative agenda. Employee Rights and Employment Policy Journal, 8, 423-453.

Paustian-Underdahl, S. C., Walker, L. S., \& Woehr, D. J. (2014). Gender and perceptions of leadership effectiveness: A meta-analysis of contextual moderators. Journal of Applied Psychology. https:// doi.org/10.1037/a0036751

Pearce, C. L., \& Sims, H. P. (2002). Vertical versus shared leadership as predictors of the effectiveness of change management teams: An examination of aversive, directive, transactional, transformational, and empowering leader behaviors. Group Dynamics. https://doi.org/10.1037/1089-2699.6.2.172

Pearce, C. L., Sims, H. P., Cox, J. F., Ball, G., Schnell, E., Smith, K. A., \& Trevino, L. (2003). Transactors, transformers and beyond: A multi-method development of a theoretical typology of leadership. Journal of Management Development. https://doi.org/10.1108/02621710310467587

Pearson, C. M., Andersson, L. M., \& Porath, C. L. (2000). Assessing and attacking workplace incivility. Organizational Dynamics, 29, 123-138.

Pelz, D. C. (1956). Some Social Factors Related to Performance in a Research Organization. Administrative Science Quarterly. https://doi.org/10.2307/2390926

Rayner, C., Hoel, H., \& Cooper, C. L. (2002). Workplace Bullying: What We Know, Who is to Blame, and What We Can Do. Taylor \& Francis.

Rayner, C. (1997). The Incidence of Workplace Bullying. Journal of Community \& Applied Social Psychology, 7(3), 199-208. https://doi.org/10.1002/(SICI)1099-1298(199706)7:3\%3c199::AIDCASP418\%3e3.0.CO;2-H

Rayner, C., \& Cooper, C. (1997). Workplace bullying: Myth or reality - can we afford to ignore it? Leadership \& Organization Development Journal. https://doi.org/10.1108/01437739710182313

Robert, V., \& Vandenberghe, C. (2020). Laissez-Faire Leadership and Affective Commitment: The Roles of Leader-Member Exchange and Subordinate Relational Self-concept. Journal of Business and Psychology. https://doi.org/10.1007/s10869-020-09700-9

Rosette, A. S., \& Tost, L. P. (2010). Agentic Women and Communal Leadership: How Role Prescriptions Confer Advantage to Top Women Leaders. Journal of Applied Psychology. https://doi.org/ 10.1037/a0018204

Sheehan, M., Barker, M., \& Rayner, C. (1999). Applying strategies for dealing with workplace bullying. International Journal of Manpower. https://doi.org/10.1108/01437729910268632 
Simpson, A. V., Farr-Wharton, B. S. R., \& Reddy, P. (2019). Correlating workplace compassion, psychological safety and bullying in the healthcare context. Academy of Management Proceedings. https:// doi.org/10.5465/ambpp.2019.16632abstract

Skogstad, A., Einarsen, S., Torsheim, T., Aasland, M. S., \& Hetland, H. (2007). The destructiveness of laissez-faire leadership behavior. Journal of Occupational Health Psychology. https://doi.org/10.1037/ 1076-8998.12.1.80

Skogstad, A., Torsheim, T., Einarsen, S., \& Hauge, L. J. (2011). Testing the work environment hypothesis of bullying on a group level of analysis: Psychosocial factors as precursors of observed workplace bullying. Applied Psychology. https://doi.org/10.1111/j.1464-0597.2011.00444.x

Stewart, G. L., Courtright, S. H., \& Manz, C. C. (2011). Self-leadership: A multilevel review. Journal of Management, 37(1), 185-222. https://doi.org/10.1177/0149206310383911

Stewart, G. L., \& Manz, C. C. (1995). Leadership for Self-Managing Work Teams: A Typology and Integrative Model. Human Relations. https://doi.org/10.1177/001872679504800702

Sutton, R. I. (2018). The Asshole Survival Guide: How to Deal with People Who Treat You Like Dirt. Mariner Books, Houghton Mifflin Harcourt.

Sweeny, A. B., Fietchner, L. A., \& Samores, R. J. (1975). An integrative factor analysis of leadership measures and theories. Journal of Psychology, 90, 75-85.

Taylor, S. G., Kluemper, D. H., \& Locklear, L. R. (2018). Is incivility really tit-for-tat? Experienced and instigated incivility in dyadic relationships. Academy of Management Proceedings. https://doi.org/10. 5465/ambpp.2018.10553abstract

Tepper, B. J. (2000). Consequences of abusive supervision. Academy of Management Journal. https://doi. org/10.2307/1556375

Tepper, B. J., Duffy, M. K., \& Shaw, J. D. (2001). Personality moderators of the relationship between abusive supervision and subordinates' resistance. Journal of Applied Psychology. https://doi.org/10.1037/ 0021-9010.86.5.974

Trapnell, P. D., \& Paulhus, D. L. (2012). Agentic and communal values: Their scope and measurement. Journal of Personality Assessment. https://doi.org/10.1080/00223891.2011.627968

Useem, J. (2015, June). Why it pays to be a jerk. The Atlantic.

Valentine, S. R., Hanson, S. K., \& Fleischman, G. M. (2017). The Spiraling and Spillover of Misconduct: Perceived Workplace Bullying, Subclinical Psychopathy, and Businesspersons' Recognition of an Ethical Issue. Employee Responsibilities and Rights Journal. https://doi.org/10.1007/ s10672-017-9302-8

Wang, M. L., \& Hsieh, Y. H. (2016). Do gender differences matter to workplace bullying? Work. https://doi. org/10.3233/WOR-152239

Watson, J. (2008). The Philosophy and Science of Caring. University Press of Colorado.

Wech, B. A., Howard, J., \& Autrey, P. (2020). Workplace Bullying Model: A Qualitative Study on Bullying in Hospitals. Employee Responsibilities and Rights Journal. https://doi.org/10.1007/ s10672-020-09345-Z

Wellman, N., Newton, D. W., Wang, D., Wei, W., Waldman, D. A., \& LePine, J. A. (2019). Meeting the need or falling in line? The effect of laissez-faire formal leaders on informal leadership. Personnel Psychology. https://doi.org/10.1111/peps.12308

Yukl, G. (1998). Leadership in Organizations (4th ed.). Prentice-Hall.

Zapf, D. (1999). Organisational, work group related and personal causes of mobbing/bullying at work. International Journal of Manpower, 20(1/2), 70-85. https://doi.org/10.1108/01437729910268669

Zhang, S., \& Leidner, D. (2018). From improper to acceptable: How perpetrators neutralize workplace bullying behaviors in the cyber world. Information and Management. https://doi.org/10.1016/j.im.2018. 03.012 